\title{
A sociologia da imigracão no Brasil entre as décadas de 1940 e 1970
}

\section{Márcio de Oliveira*}

\section{Resumo}

Entre os anos 1940 e 1970, no Brasil, os estudos imigrantistas rivalizaram com os estudos comunitários, rurais e indígenas. Em termos teóricos, todos eles trabalharam com a mesma temática de assimilação à sociedade nacional. Revistas tais como Sociologia (ELSP), Revista de Antropologia, Revista do Museu Paulista e Anhembi acolheram diversos trabalhos sobre imigrantes, resultados de pesquisas feitas por autores tais como Emílio Willems, Hiroshi Saito e Ruth Cardoso. Florestan Fernandes interessou-se pelo tema, tendo publicado três artigos sobre a imigração árabe no Brasil. Nos anos 1970, contudo, o tema perdeu interesse. Sociólogos brasileiros interessaram-se por outros temas, tais como classes sociais e desenvolvimento nacional. Este trabalho volta ao período em tela para, analisando a trajetória dessa produção sobre o tema da imigração, compreender sua importância e perda de centralidade no seio da sociologia brasileira. Focamos a análise no período que vai de 1930 a 1970, quando a produção sociológica sobre o tema foi numerosa, tomando como fonte de informação tanto as principais revistas da área quanto livros publicados, a fim de compreender qual o lugar e o papel desempenhado pelos estudos sobre imigração na sociologia brasileira.

Palavras-chave: Sociologia brasileira, Imigração, Estudos sobre imigração.

* Universidade Federal do Paraná (UFPR), Curitiba, PR, Brasil. 


\section{The sociology of immigration in Brazil between the 1940s and $1970 s$}

\section{Abstract}

Between the 1940s and 1970s, in Brazil, immigrant studies competed with community, rural, and indigenous studies. As regards theory, all of them worked with the same theme of assimilation to the national society. Journals such as Sociologia (ELSP), Revista de Antropologia, Revista do Museu Paulista and Anhembi have published several papers on immigrants, describing the finding of researches conducted by authors such as Emílio Willems, Hiroshi Saito and Ruth Cardoso. Florestan Fernandes was interested in the subject, having published three articles on Arab immigration in Brazil. Nevertheless, in the 1970s, the theme lost interest. Brazilian sociologists changed their focus to the studies on social class and national development. The present work returns to that specific period to analyze the trajectory of this production on the subject of immigration, seeking to understand its importance and loss of centrality within Brazilian sociology. We focused our analysis in the period from 1930 to 1970 , when the sociological production on the subject was numerous, taking as source of information both the main journals of the area and books published, in order to understand the place and the role played by the immigrant studies in Brazilian sociology.

Keywords: Brazilian sociology, Immigration, Immigrant studies

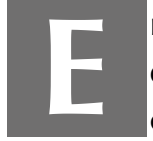

ntre os anos 1940 e 1970, o tema da imigração foi objeto de pesquisa dos mais importantes sociólogos e antropólogos, rivalizando com os estudos indígenas, comunitários e rurais. Revistas tais como Sociologia (ELSP), Revista de Antropologia, Revista Brasiliense, Revista do Museu Paulista e Anhembi acolheram trabalhos sobre imigrantes feitos por cientistas sociais bastante conhecidos, tais como Camilo Cecchi, Egon Schaden, Emílio Willems, Eunice Ribeiro Durhan, Gioconda Mussolini, José Arthur Rios, Hermelina Maria Pretto, Hiroshi Saito, Maria Isaura Pereira de Queiroz, Octávio lanni, Renato José da Costa Pacheco, Ruth Cardoso, Seiichi Izumi e Vicente Unzer de Almeida, dentre outros. Florestan Fernandes também se interessou pelo tema, tendo publicado uma resenha sobre o livro de Willems lançado em 1940, dois artigos sobre imigrantes árabes no Brasil e um último, 
em 1966, quando retomou a relação entre o tema da imigração e aquele das relações raciais (Fernandes, 1949; 1956a; 1956b; 1966). Além desses trabalhos, analisou a questão imigrante em vários de seus livros. ${ }^{1}$ Lembremos enfim que, em termos teóricos, os estudos acima, independente da abordagem antropológica ou sociológica escolhida, compartilharam aparelho conceitual, como é possível observar nos livros Assimilação de populações marginais do Brasil, escrito por Emílio Willems (1940) e O Processo de Assimilação dos Terena, escrito por Roberto Cardoso de Oliveira (1976 [1960])².

O tema perdeu lentamente sua importância durante a década de $1970^{3}$. Naqueles anos, apenas alguns artigos, poucos livros - Imigração e a Crise do Brasil Agrário, de José de Souza Martins (1973), Assimilação e integração dos japoneses no Brasil, organizado por Hiroshi Saito e Takashi Mayema (1973) ou Italianos no mundo rural paulista, de João B. B. Pereira (1973) - e os fóruns de estudos ítalo-brasileiros ${ }^{4}$ trataram da temática imigrantista. Ao final daquela década, o fenômeno da imigração praticamente inexistia na sociologia ${ }^{5}$, parecia estar restrito ao domínio da historiografia, enquanto que, na antropologia, teria se tornado secundário, apesar das fundamentais contribuições de Giralda Seyferth e João B. B. Pereira. De certa maneira,

1 A carreira e obra de Florestan tem sido objeto de inúmeras análises, tais como Incao (1987), Soares (1997), Bastos (1998), Garcia (2002), Arruda e Garcia (2003), Arruda (2009), Brasil Jr. (2010), Blanco e Jackson (2014), entre outros. Não obstante, exceção feita à Arruda (2009), Brasil Jr. (2010) e Blanco e Jackson (2014), nota-se o pequeno espaço dedicado à sua contribuição ao tema da imigração, objeto de outra pesquisa que ora desenvolvemos.

${ }^{2}$ Trabalhamos aqui com a segunda edição, publicada em 1976, que teve seu título levemente modificado para "Do Índio ao Bugre. O processo de assimilação dos Terena."

${ }^{3}$ Lopes e Vilela (2011) definem o ano de 1970 como um turning point. Naquela década, o fluxo migratório para o Brasil diminui bastante. A partir dos anos 1980, o fluxo voltou a crescer, em especial com os imigrantes sul-americanos, embora o saldo migratório seja negativo até 1990. Os maiores fluxos datam dos anos 1990 em diante. Para maiores detalhes, ver Patarra (2005) e Baeninger (2012).

4 Publicados pelo Instituto Superior Brasileiro-Italiano de Estudos e Pesquisas (1979). Vide referências bibliográficas.

${ }^{5} \mathrm{Na}$ Sociologia, o tema voltaria a ter destaque apenas nos anos 1990, com estudos sobre brasileiros residentes nos países centrais. Na Sociedade Brasileira de Sociologia, institucionalizou-se apenas no Congresso de 2017, quando foi criado um Grupo de Trabalho. Não obstante, a partir dos anos 1990, o tema ganhou destaque nos estudos demográficos e estava em muitos artigos na Revista Brasileira de Estudos Populacionais (www.rebep.org.br), editada pela Associação Brasileira de Estudos Populacionais (ABEP). 
era como se a categoria imigrante não mais explicasse as práticas sociais dos imigrantes e seus descendentes ou talvez porque se acreditasse que eles já estariam "abrasileirados" e já não se diferenciavam necessariamente de outros grupos e classes sociais. Assim, passaram a ser analisados sob outras perspectivas, mormente a partir de seus perfis profissionais, inserções produtivas e classes a que pertenciam ${ }^{6}$. Em termos conceituais, a mudança foi também profunda. O conceito de classe social substituíra com sobras os conceitos de etnia e de integração, com sobras o conceito de aculturação. Dos tradicionais estudos das décadas anteriores, sobravam apenas as questões indígena e racial, transformadas em reais problemas que desafiavam a construção da cidadania e da moderna democracia.

A mudança ocorrida nos anos $1990^{7}$, de país imigrantista para país emigrante, contribuiu para o eclipse (pois não desapareceram) do número de trabalhos e pesquisas realizados sobre imigrantes e descendentes, dificultando tanto situar quanto compreender a produção realizada entre as décadas de 1940 e 1970, assim como seu papel na história das ciências sociais ou, mais especificamente, da sociologia brasileira ${ }^{\mathbf{8}}$. Quais eram as referências conceituais utilizadas? Elas estavam em sintonia com aquilo que se produzia alhures? Em que medida dialogavam com outros campos de estudo? Como explicar o declínio posterior? Para responder a essas questões, trabalhamos com a hipótese geral segundo a qual havia, no período examinado, grande proximidade (não

\footnotetext{
${ }^{6}$ Não queremos dizer com isso que a perspectiva classista estava ausente das análises sociológicas do período anterior. Nos anos 1940, segundo Guimarães (1999), o conceito era pensado de duas formas: em termos de estratos sociais (Pierson, 1948; Willems, 1948) ou como elementos da estrutura social (Fernandes,1948).

${ }^{7}$ Segundo dados do Itamaraty (www.itamaraty.gov.br), desde os anos 1990 o Brasil vem produzindo mais expatriados do que atraindo imigrantes. De fato, há hoje mais brasileiros vivendo no exterior (pouco mais de 3 milhões) do que estrangeiros vivendo no Brasil (em torno de 1,8 milhão segundo a Pastoral do Migrante, enquanto que para o Ministério da Justiça, o número seja apenas de 1 milhão), o que justifica o fato de considerarmos o Brasil como um país emigrante. Para maiores detalhes, ver Patarra (2005).

${ }^{8}$ Entre 1970 e 1990, os antigos temas e conceitos foram preteridos em favor das análises sobre estrutura de classes e conflitos sociais. Mesmo o tema das migrações internas superou aquele das migrações internacionais. Para maiores detalhes ver Assis, Sasaki e Sales (2003).
} 
apenas no Brasil) entre Sociologia e Antropologia9 em relação aos temas de pesquisas, abordagens teórico-metodológicas, em especial com os estudos rurais, comunitários e indígenas. Analisando não exaustivamente algumas das principais obras sobre imigrantes publicadas em forma de livro ou como artigos nas revistas Sociologia e Revista de Antropologia, procuramos demonstrar que os imigrantes foram compreendidos como grupos relativamente à margem do Brasil que se modernizava, tal como as comunidades rurais e indígenas. Pensados a partir da sociedade nacional, seu destino deveria ser a assimilação à mesma. Isso praticamente selou o interesse específico que despertavam, postergando, assim, a institucionalização da sociologia da imigração, que somente se reergueria, lentamente, a partir de meados dos anos 1980.

\section{O campo das ciências sociais brasileiras nos anos 1930-1950: elementos de indiferenciação e progressiva autonomia disciplinar}

O mundo acadêmico brasileiro foi radicalmente modificado no início dos anos 1930, com a criação de algumas das principais universidades que existem até hoje. Na cidade de São Paulo foram criadas quase que simultaneamente a Universidade de São Paulo e a Escola Livre de Sociologia e Política que compartilharam professores (caso de Emílio Willems) e alunos (Gioconda Mussolini ${ }^{10}$ e Florestan Fernandes, entre outros). Na cidade do Rio de Janeiro, em parceria com o Museu Nacional ${ }^{11}$, foi criada, em 1935, a Universidade do Distrito Federal. Limongi (1989) e Massi (1989) mostram como, no processo de institucionalização do ensino e da pesquisa e na organização das primeiras publicações em Ciências Sociais, foram decisivos alguns professores estrangeiros, tais como Pierre Monbeig, Fréderic Mauro, Fernand Braudel, Emílio Willems, Donald Pierson, Roger Bastide e Georges

\footnotetext{
${ }^{9}$ Em função do caráter interdisciplinar do tema, muitos estudos foram provenientes de áreas afins às ciências sociais - geografia, história etc. - tendo sido igualmente publicados nas mesmas revistas.

${ }^{10}$ Sobre a trajetória de Gioconda, falecida precocemente em 1969, ver Ciacchi (2007).

11 Isso ocorreu, em parte, devido à atuação de Edgard Roquette-Pinto, diretor do Museu Nacional entre 1926 e 1935.
} 
Gurvitch. Como um todo, nas ciências sociais de então, havia reflexões de caráter sociológico, antropológico, em pesquisas oriundas da Filosofia, Economia, da História, da Literatura, da Geografia, da Antropologia Física, e mesmo da Biologia e da Medicina. Liedke Filho (2005) afirma, porém, que nesse período impôs-se uma divisão, separando "a herança históricocultural da sociologia" da "etapa contemporânea da sociologia", cujo último período, também chamado de "sociologia crítica", teria se beneficiado largamente da chegada dos professores estrangeiros acima.

Nas décadas de 1930 e 1940, tanto nos cursos da Escola Livre de Sociologia e Política (ELSP) quanto da Universidade de São Paulo (USP), a diferenciação entre sociologia e antropologia ainda era sutil. Isso não era uma característica intrinsecamente brasileira. Fora, de certo modo, herdada do mundo acadêmico francês, justamente de onde chegavam, em diferentes levas, a maior parte dos professores, mas também do mundo acadêmico norteamericano, em especial do Departamento de Sociologia da Universidade de Chicago, onde Donald Pierson, um dos primeiros professores da ELSP havia se formado com uma tese sobre relações raciais na Bahia.

Na França do início do século XX, Émile Durkheim atribuiu grande crédito à antropologia que se fazia na Inglaterra, em especial aos trabalhos sobre os Arunta ${ }^{12}$, que forneceram material empírico para as análises que deram origem ao livro As Formas Elementares da Vida Religiosa (Durkheim, 2002) e ao artigo Algumas formas de classificação primitiva (Durkheim; Mauss, 1981), escrito em conjunto com Marcel Mauss. É certo, também, que mesmo Mauss pouco diferenciou Sociologia e Antropologia, como se pode ver, por exemplo, em La Sociologie. Objet et méthode (1901, escrito em parceria com Paul Fauconnet), Appréciation Sociologique du Bolchevisme (1924), La cohésion sociale dans les sociétés polysegmentaires

12 Trata-se de um dos grupos indígenas australianos estudados pelos antropólogos Francis J Gillen e Walter B. Spencer no livro The native tribes of central Australia (1899). Durkheim e Mauss publicaram dois artigos sobre os Arunta, disponíveis no sítio http://classiques.uqac.ca/ classiques/mauss_marcel/mauss_marcel.html 
(1931), La Sociologie en France de 1914 à 1933 (1933), Fragments d'un Plan de Sociologie Cénérale Descriptive (1934), entre outros ${ }^{13}$.

O progressivo afastamento entre antropologia e sociologia, ocorrido lentamente ao longo da primeira metade do século XX, pode ser lido em diversos níveis. No nível temático, inicialmente, havia muita proximidade de objetos pesquisados tanto na França quanto nos EUA, ainda que a história das ciências sociais nesse último país tenha se vinculado mais à ideologia do American exceptionalism, auferindo menos importância à diferenciação disciplinar (Ross, 1991). Nas primeiras décadas do século XX, na Universidade de Chicago, os principais temas de estudo eram relações raciais, grupos étnicos e imigrantes. Nenhum desses objetos apresentava ainda os contornos disciplinares que adquiririam décadas mais tarde.

Il faut rappeler d'abord que le domaine des travaux sur les relations entre races et entre groupes ethniques (je reviendrais plus loin sur ces appellations) ne s'est jamais inscrit dans un cadre strictement disciplinaire. Sociologues, anthropologues, économistes, historiens et chercheurs indépendants sans rattachement à une discipline universitaire ont participé au même domaine d'études, sans que le rattachement disciplinaire constitue un obstacle à la diffusion de leurs analyses parmi leurs collègues relevant $d$ 'autres disciplines. (Chapoulie, 2001, p. 292).

Segundo Chapoulie, o artigo Race and Culture, publicado em 1913 pelo sociólogo de Chicago, Robert Park (1864-1944), é um excelente indicador da perspectiva sociológico-antropológica com a qual se trabalhava ainda nos anos 1930:

Le cadre conceptuel que définit cet essai comprend donc une conception de la notion de race, une esquisse de définition de l'assimilation et l'hypothèse centrale de la sociologie des contacts entre races et entre cultures de Park : les contacts face à face et personnels sont la voie qui peut conduire à l' assimilation. Dans ce cadre, Park esquisse une interprétation de l'histoire des relations raciales dans le sud des États-Unis et formule prudemment une hypothèse concernant leur évolution à venir. (Chapoulie, 2001, p. 317).

13 Todos esses textos, com exceção de "Appréciation sociologique du bolchevisme", estão disponíveis em http://classiques.uqac.ca/classiques/mauss_marcel/mauss_marcel.html 
O tema das relações inter-raciais transitava claramente dos estudos antropológicos sobre a raça àqueles mais tipicamente sociológicos, analisados sob o prisma dos contatos face a face. É interessante pensar que o termo assimilação não indicava ainda, em nenhum dos dois lados do Atlântico, nenhuma clivagem entre antropologia, sociologia e história, como mostrou em detalhe Green (2008). O mesmo pode ser dito do conceito que lhe era correlato: comunidade (Nisbet,1993; Schrecker, 2006).

Retornando agora ao mundo paulista dos anos 1940, a proximidade entre antropologia e sociologia pode ser lida também em termos puramente científicos. Apesar da construção de espaços editoriais distintos, tanto para a sociologia (Sociologia nos anos 1940) quanto para a antropologia (Revista de Antropologia, 1953), as fronteiras não estavam demarcadas, como mostram Peixoto e Simões, referindo-se especificamente à Revista de Antropologia:

A leitura dos 20 primeiros números da publicação (1953-1972) confirma essa imbricação entre sociologia e antropologia em parte significativa da antropologia produzida em São Paulo, e que pode ser aferida pelas colaborações regulares de sociólogos da USP e da ESP, assim como pela forte presença dos estudos de comunidade e das pesquisas sobre contato e assimilação, que articulam de perto as perspectivas antropológica e sociológica. (Peixoto; Simões, 2003, p. 388).

Eunice Durham, sobre a qual retornamos abaixo, afirma que a agenda da antropologia da época estava mais ligada à sociedade nacional do que às sociedades indígenas e que havia uma "antropologia em estreita colaboração com a sociologia" (Durham apud Peixoto; Simões, 2003, p. 389-90). O principal tema de então, e para o qual convergiam as abordagens sociológicas e antropológicas, girava em torno de questões de interesse nacional, incluídas aí as pesquisas classificadas como "estudos de comunidade"14. Contudo, os estudos comunitários seriam alvo da crítica primeira de Florestan Fernandes (1958), para quem eles ainda não haviam consolidado um "modelo positivo" de pesquisa e, em seguida, daquela feita por Octávio lanni (1961), que apontava seus limites heurísticos além da ausência da problemática cara

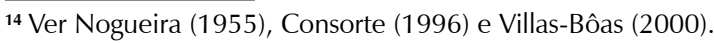


à análise da mudança social: o conflito. Isso explica porque esses estudos teriam sido lentamente abandonados no bojo do processo de cientificização e de modernização das ciências sociais brasileiras (Consorte, 1996; Koffes, 1996). Porém, para o que nos importa aqui, essas críticas causaram também grande impacto nos estudos imigrantistas.

\section{Os estudos sobre grupos imigrantes e comunidades rurais: proximidade temático-conceitual e mesmo destino?}

Emílio Willems (1905-1997) é, talvez, o autor que mais tenha marcado tanto os estudos imigrantistas quanto os estudos de comunidade realizados no Brasil entre os anos 1930 e $1950^{15}$. Seu primeiro trabalho, Assimilação e populações marginais no Brasil (Willems, 1940), utiliza dois conceitos emprestados da sociologia norte-americana: o conceito de assimilação (Fairchild, [1913] 1941 ${ }^{16}$ ) e o conceito de marginal man (Park, 1928). O tema geral do livro são os contatos entre imigrantes e locais. Nele, inicialmente, o autor afirma que a miscigenação entre imigrantes alemães e população nativa não estava acontecendo: "Não existe assimilação em si" (Willems, 1940, p. 11). Assim, não haveria porque pensar em total perda da identidade cultural do grupo migrante, nem mesmo, por conseguinte, em assimilação. No artigo que publicou em inglês, apenas alguns anos após esse primeiro livro, Willems (1944) utilizou o conceito de aculturação. Nessa nova publicação, afirmou que os "germano-brasileiros" (German-Brazilians) não estavam se assimilando à cultura nacional; estavam apenas incorporando valores da cultura gaúcha graças, por exemplo, à aquisição de "cavalos selados", descoberta da qual valeu-se para justificar a opção pelo conceito de aculturação em

\footnotetext{
${ }^{15}$ Nascido na cidade de Colônia (Alemanha), chegou ao Brasil em 1931 para lecionar no seminário da cidade de Brusque. Em 1934, convidado por Fernando de Azevedo, iniciou carreira na USP, onde obteve o título de livre-docente em 1937, e na ELSP. Florestan Fernandes, Gioconda Mussolini e Miriam Moreira Leite, entre outros, foram seus alunos. Mudou-se para os EUA em 1949, onde permaneceu até sua morte. Para maiores detalhes ver Pereira (1994) e Villas-Bôas (2000).

${ }^{16}$ Nesse trabalho, Willems critica o processo assimilação de imigrantes tal como proposto por Fairchild (1941), ou seja, como processo de abandono da nacionalidade anterior e adoção da nova da sociedade de destino.
} 
detrimento do conceito de assimilação ${ }^{17}$. Através da aquisição dos cavalos, os descendentes logravam, a um só tempo, ascender economicamente e distinguir-se socialmente. Esse processo de aculturação estava na origem da formação de comunidades teuto-brasileiras, expressão que ele então propôs.

O tema da mudança cultural foi definitivamente explorado no segundo livro publicado. Nele, Willems (1946) reforçou a tese do artigo de 1944, focando suas análises nos processos de "aculturação dos alemães". Através de exemplos retirados dos inúmeros arranjos sociais produzidos - família, escola, literatura, língua, todos eles denominados "teuto-brasileiros" -, afirmou que o insulamento das comunidades de imigrantes tinha sido apenas parcial, embora a nascente cultura teuto-brasileira fosse ainda uma "cultura marginal". Numa palavra, naqueles novos trabalhos, a mudança cultural (e não o processo de assimilação) era a chave analítica que lhe permitiu compreender a trajetória das comunidades rurais de imigrantes alemães ${ }^{18}$, indicando, precocemente, o surgimento de áreas multiculturais no interior do Brasil. O autor se valeria ainda da mesma opção teórica em seus estudos sobre imigrantes japoneses (Willems, 1948) ${ }^{19}$. Nesse meio tempo, porém, exatamente em 1945, Willems publicou um artigo sobre "a assimilação de judeus" perseguidos pelo nazismo. Mais do que uma análise sobre um grupo específico de imigrantes, o foco foi a Segunda Guerra Mundial e seus impactos sobre a dispersão e assimilação dos judeus que fugiam e se refugiavam em vários países do mundo, inclusive no Brasil. Esse grupo, em princípio, parecia deixar-se assimilar, não produzindo arranjos culturais novos ou híbridos.

Em 1947, com Hiroshi Saito, Willems publica Shindô-Renmei. Um problema de aculturação. Nesse artigo, a preocupação central foi compreender o impacto da sociedade "Shindô-Renmei" na assimilação de japoneses a ela associados. Uma vez que o objetivo da Sociedade era "salvar imigrantes japoneses para o Japão", a pregação antiassimilacionista dos líderes da Shindô-

17 Nesse ínterim, exatamente em 1942, na Escola Livre de Sociologia Política, Willems ministrou um curso intitulado "Assimilação e Aculturação".

${ }^{18}$ Para uma discussão sobre o termo, ver, entre outros, Doytcheva (2011) e Macagno (2014).

${ }^{19}$ Como ele próprio explica no prefácio do livro sobre a aculturação dos alemães (Willems, 1946), a eclosão da Segunda Guerra Mundial impediu a continuidade da pesquisa. 
Renmei foi tratada como um "disfarce ideológico" (e não propriamente uma opção teórica) cujo objetivo era impedir os processos aculturativos (Saito, Willems, 1947). Finalmente, em 1953, Willems publica um último estudo. Tratou então das escolhas matrimoniais de descendentes de alemães, excluindo as "áreas uniformemente germânicas", onde praticamente não havia opções matrimoniais fora da comunidade. Afirmou, então, que nos espaços urbanos os descendentes estavam ampliando o leque de escolhas matrimoniais tanto em direção aos descendentes de outros grupos imigrantes quanto em direção aos brasileiros de origem luso-portuguesa. Em forma de conclusão, o autor afirmou, contudo, que a "assimilação, pelo menos parcial, é anterior à miscigenação" (Willems, 1953, p. 345). Contudo, como entender a oscilação no uso desses conceitos? Ambos teriam sido usados de forma intercambiável ou devemos ver aí uma mudança teórica de relevo? A leitura desses trabalhos indica que a opção de Willems pelo conceito de aculturação não se fez em oposição nem aos processos de miscigenação nem ao conceito de assimilação, mas de forma a melhor descrever os primeiros e melhor caracterizar o último. O conceito de aculturação parecer ter-lhe servido para traduzir hibridismos culturais impossíveis de serem pensados quando o termo de assimilação era usado. Em resumo, os trabalhos de Willems (1940; $1944 ; 1945 ; 1946 ; 1948 ; 1953)$ indicam uma lenta mudança do modelo racial-assimilacionista, no qual o uso do termo assimilação foi praticamente absoluto, para o modelo das transformações culturais, no qual a preferência recaiu sobre o conceito de aculturação. Porém, em que medida as escolhas e perspectivas de Willems eram consensuais? Que tipo de uso desses conceitos encontramos em outros autores?

No campo dos estudos migratórios no Brasil, o conceito de assimilação foi utilizado pela primeira vez pelo historiador e sociólogo paulista Alfredo Ellis Jr. (1896-1974), em trabalho sobre populações paulistas (Ellis Jr., 1934)20. Naquele momento, contudo, o conceito tinha um nítido sentido biológicoracial. Esse sentido seria mantido também por Francisco José de Oliveira

${ }^{20}$ Ultrapassa o quadro desse trabalho uma análise aprofundada sobre as semelhanças entre a perspectiva assimilacionista e os estudos eugênicos. Esse assunto foi trabalhado em detalhes por Stepan (2005). 
Vianna (1934) e nos trabalhos de Arthur Ramos dos anos 1940 (Truzzi, 2012, p. 519) ${ }^{21}$. Freyre, no pequeno livro Continente e ilha, também fez referências à assimilação dos "imigrantes no sul do Brasil" (Freyre, 1943). Finalmente, em trabalhos de outros autores, como mostrado abaixo, é possível verificar a utilização do conceito de assimilação indicando processos de mudança cultural.

Quadro 1. Artigos sobre assimilação de imigrantes

\begin{tabular}{cccc}
\hline Autor & Título & Periódico & ano \\
\hline Aluízio Azevedo & Assimilação & Sociologia & 1941 \\
Renato Almeida & $\begin{array}{c}\text { O folclore como elemento } \\
\text { nacionalizador dos colonos estrangeiros }\end{array}$ & $\begin{array}{c}\text { Revista de Imigração e } \\
\text { Colonização } \\
\text { Aślio Willems }\end{array}$ & 1943 \\
$\begin{array}{c}\text { Maria Isaura P de } \\
\text { Queiroz }\end{array}$ & $\begin{array}{c}\text { Assimilação de três famílias em São } \\
\text { Paulo }\end{array}$ & Sociologia & 1945 \\
Camilo Cecchi & $\begin{array}{c}\text { Estudo comparativo da assimilação e } \\
\text { marginalidade do imigrante italiano }\end{array}$ & 1950 \\
José Arthur Rios & Aspectos políticos da assimilação do & Sociologia & 1957 \\
Renato José Costa & italiano no Brasil & Sociologia & 1958 \\
Pacheco & $\begin{array}{c}\text { Assimilação de alemães no } \\
\text { Espírito-Santo }\end{array}$ & Sociologia & 1964 \\
Eunice Durham & Assimilação e mobilidade & $\begin{array}{c}\text { Instituto de Estudos } \\
\text { Brasileiros }\end{array}$ & 1966 \\
\hline
\end{tabular}

Fonte: $\mathrm{O}$ autor.

Em Almeida (1943), o folclore atua como prática cultural, ou melhor, como elemento indicador de um processo de aculturação. Analisando famílias de imigrantes de diversas origens (Japão, Inglaterra e Armênia), instaladas no estado de São Paulo, Queiroz (1950, p. 22-31) afirma que a assimilação consistia em processo de ajuste "a novos valores culturais", para concluir que a "observação destas famílias mostra que houve assimilação, embora em grau diferente [...]". Rios, em estudo sobre o "italiano no Brasil", demonstrou a existência de um tipo ítalo-brasileiro "nacional com todos os padrões culturais da sociedade luso-brasileira". (Rios, 1958, p. 338). Pacheco, em estudo sobre

${ }^{21}$ Nesse artigo, Truzzi apresenta uma análise bastante completa sobre os diferentes usos do termo nas ciências sociais brasileiras. 
assimilação de descendentes de alemães no estado do Espírito Santo, afirmou que o objetivo de seu trabalho era "descrever o processo pelo qual a cultura brasileira está sendo adotada pelos descendentes de alemães" (Pacheco, 1964 , p. 184). Finalmente, Durham, em pesquisa sobre a assimilação do imigrante italiano no município paulista de Descalvado, afirmou que "não havia qualquer diferença significativa entre descendentes de estrangeiros e a população nacional quanto à escolaridade, nível ocupacional e propriedade de imóveis" (Durham, 1966, p. 3). Afirmou ainda que a questão da mobilidade e da ascensão social eram o resultado do desaparecimento de traços culturais particulares. Essa tomada de posição Ihe permitiu, apoiando-se no conceito de absorção proposto por Einsenstadt (1954), concluir que os descendentes de imigrantes estavam sendo, ao mesmo tempo, assimilados e aculturados:

Em suma, a investigação revelou que os imigrantes e seus descendentes estão aculturados, que se dispersaram como grupo nas diferentes esferas da sociedade local e conseguiram, no plano individual, um ajustamento psicológico integral e satisfatório. Os imigrantes estão assimilados (Durham, 1966, p. 3; grifo no original).

Nos exemplos citados, o conceito de assimilação é utilizado para descrever processos de mudança cultural e social. As análises indicavam, ainda, o limite do conceito de assimilação quando este se restringia a compreender o processo de absorção da cultura trazida pela cultura nacional. Contudo, e isso é o mais importante, a escolha e utilização dos termos assimilação, aculturação ou absorção - não necessariamente modificavam o que se pretendia explicar, ou seja, que as práticas culturais, os casamentos interétnicos, os percursos educativos, as escolhas profissionais e as migrações internas eram dimensões do processo de integração à sociedade nacional. Essa perspectiva analítica não se resumia aos estudos imigrantistas, mas estava presente também em trabalhos sobre indígenas brasileiros ${ }^{22}$, que se valiam seja do conceito de assimilação, seja ainda do conceito de aculturação.

22 Ultrapassa o escopo desse trabalho a análise dos estudos raciais. Note-se, contudo, que, em 1941, Arthur Ramos publica "Aculturação negra no Brasil", em que se serve de perspectiva analítica muito próxima àquela dos estudos indígenas e imigrantistas. 


\section{Os estudos sobre grupos de imigrantes e de indígenas: outro exemplo de proximidade conceitual}

Os primeiros estudos do antropólogo paulista Roberto Cardoso de Oliveira (1928-2006) sobre grupos indígenas no Brasil sinalizavam um processo pelo qual eles estariam "desaparecendo face a sua incorporação à sociedade nacional, seja pelo processo biológico de miscigenação, seja pelo processo etno-social de aculturação" (Cardoso de Oliveira, 1956, p. 173). Galvão (1953), por sua vez, centrou sua análise na transmissão de 'traços culturais' entre grupos indígenas, europeus e africanos, fenômeno que definiu como sendo de "aculturação":

O índio deixou de ser o foco exclusivo de interêsse e o que se procura é o conhecimento histórico e funcional da transmissão de traços culturais do indígena aos demais contingentes de nossa população em outros têrmos, a resultante do fenômeno de "'aculturação" que resultou do contacto entre índios, europeus e africanos. A caracterização da cultura dessas sociedades rurais constitui elemento indispensável para se aferirem com a necessária precisão os fenômenos de mudanças e transição que sofrem os grupos indígenas em suas relações com nossa frente pioneira. (Galvão, 1953, p. 67).

Logo após, retornou ao conceito de assimilação, ao afirmar que:

Devemos esquecer um pouco aculturação e pensar mais em assimilação. Em nossa monografia sôbre os índios Tenetehára, nos deixamos empolgar pelo ritmo relativamente acelerado de transição dessa cultura indígena para os padrões brasileiros. Embora o grupo mantenha sua unidade tribal e possa ser distinguido da população cabocla por uma configuração cultural diferente, são evidentes os sinais de desgaste da cultura tradicional e as de substituição de valores tribais por outros, brasileiros, resultantes do impacto de trezentos anos de convívio geralmente pacífico com nossa sociedade rural. Concluímos que não demoraria talvez mais que uma ou duas gerações para que os Tenetehára se transformassem em caboclos (Galvão, 1953, p. 71)

No clássico livro sobre os Terena, Cardoso de Oliveira (1976[1960]) voltou a afirmar que estavam em jogo processos de mudança cultural em direção à sociedade nacional. Ele chegou a essa conclusão a partir de 
projeto de pesquisa, elaborado em 1956, sobre "o processo de assimilação" daquele grupo indígena, quando procurou compreender os dispositivos culturais que influenciavam o largo processo de assimilação, ainda que ressaltando a persistência de traços indígenas no grupo estudado. Analisando esse trabalho, Castro (1999, p. 115) ${ }^{23}$ afirmou que a perspectiva havia sido "[...] centrada no pólo colonial, uma sociologia do Brasil indígena (Cardoso de Oliveira, 1978), que toma os índios como parte do Brasil [...]". Cardoso de Oliveira continuou a considerar os "índios como parte do Brasil" em Urbanização e tribalismo. A integração dos Índios Terêna numa sociedade de classes. Nesse novo trabalho, mostrou inclusive como os processos migratórios em direção aos espaços urbanos aceleravam a integração à sociedade nacional de classes. Com efeito, Cardoso de Oliveira parecia convencido da centralidade das mudanças sofridas como resultado do contato com a sociedade nacional. Em resumo, nesses estudos, as abordagens assimilacionista, aculturalista ou ainda dos contatos interétnicos eram todas muito próximas, ou seja, qualquer uma delas poderia explicar as consequências dos contatos entre indígenas - que ora perdiam, ora mantinham seus traços culturais distintivos - e a sociedade nacional. Tal perspectiva, percebe-se, é muito semelhante àquela que tinha sido utilizada por Willems nos estudos sobre os grupos imigrantes alemães. Com efeito, esses últimos grupos também pareceram ora mais resistentes à assimilação, ora mais aculturados, o que permitia acentuar a diferença entre os conceitos.

\section{Grupos imigrantes e/ou comunitários: da ameaça à soberania nacional à integração à sociedade classista}

Recuando um pouco no tempo, devemos lembrar que, a partir de meados dos anos 1930, as populações imigrantes do sul do Brasil passaram

${ }^{23}$ Castro (1999, p. 115-116) afirmou ainda que a "preocupação nacional", centrada no "olhar objetivante do Estado nacional" é (portanto, continuou a ser desde então até 1999, quando ele publicou sua análise), a "principal característica da antropologia brasileira", embora não seja a "contribuição teórica mais original". 
a ser consideradas perigosas. Dizia-se amiúde que viviam de forma isolada, em quistos étnicos que "ameaçavam a soberania nacional". Dentre elas, as comunidades teuto-brasileiras foram consideradas aquelas menos nacionalizadas e mais ameaçadoras ${ }^{24}$. Foram essas, justamente, as mais visadas pela chamada Campanha de Nacionalização, desencadeada em 1939 pelo governo Vargas ${ }^{25}$, e cujo ponto de partida foi a obrigação do ensino em português em todas as escolas e a demissão dos professores que ministravam cursos regulares em língua estrangeira ${ }^{26}$.

Além dos teuto-brasileiros, outros grupos foram também visados pela Campanha. Em Curitiba, durante a Segunda Guerra Mundial, descendentes de poloneses foram objeto de maus-tratos e encarcerados pela segurança pública (Boschilia, 1995). O jovem oficial Hugo Bethlem dedicou-lhes uma longa análise, em que afirmou ter ficado surpreso com o "grau de desnacionalização" daqueles núcleos rurais poloneses espalhados no interior de Santa Catarina e do Paraná e tidos por "inofensivos" (Bethlem, 1939, p. 54-60). Ainda que o contexto do início da Segunda Guerra explique muitas das afirmações dirigidas às colônias rurais de imigrantes, é possível afirmar que o grau de inserção à sociedade nacional aproxima o temor ressentido da perspectiva usada para analisar tanto os grupos indígenas quanto os grupos de imigrantes e descendentes. Dito de outra forma, ambos os grupos foram pensados a partir da - mas também em oposição à - sociedade nacional. Porém, embora vivendo em situação

${ }^{24}$ A ascensão do nazismo e o desejo de Hitler de criar no Brasil uma "Alemanha no estrangeiro" em muito contribuíram para a disseminação da tese da "ameaça à soberania nacional". Com efeito, entre 1933 e 1939, o Partido Nazista brasileiro estava presente em 17 estados e sua propaganda era direcionada exclusivamente para as comunidades teutobrasileiras. Ver Brepohl de Magalhães (1998).

${ }^{25}$ Decreto-lei no 481 (1938) introduziu nos currículos escolares os cursos de moral e de civismo, que ficaram a cargo de militares. Já o decreto no 1.545 (1939) proibiu o emprego de línguas estrangeiras em espaços públicos, inclusive nas escolas, associações culturais e igrejas. Além disso, proibiu também as transmissões radiofônicas e os jornais em língua estrangeira. Ver Campos (2006) e Ribeiro (2012).

${ }^{26}$ Às vésperas da Segunda Guerra, 70\% dos membros das comunidades teuto-brasileiras (aproximadamente 640 mil indivíduos) comunicavam-se apenas em alemão e recusavam os chamados casamentos mistos. Para maiores detalhes, ver Oliveira (2008) e Campos (2006). 
de parcial isolamento, nenhum deles estava imune à sociedade nacional. Ao contrário, sofriam os mesmos processos aculturativos ou de mudança cultural analisados por Willems ou por Cardoso de Oliveira. Assimilar ou aculturar dizia respeito aos contatos interétnicos, em prejuízo dos grupos minoritários, fossem eles indígenas ou imigrantes. Porém, em resumo, análises sobre populações radicalmente diferentes entre si partilharam tanto o universo teórico (assimilação, aculturação e integração) quanto a perspectiva analítica (mudanças culturais e processos adaptativos). A explicação para isso talvez esteja nos espaços rurais (cujos graus de isolamento variavam, é claro) onde viviam e no caráter comunitário de sua organização social.

Wagley (1954) afirma que os estudos sobre comunidades ${ }^{27}$ no Brasil tiveram por objeto "segmentos localizados de nações modernas ou civilizações". Eram estudos sobre grupos que viviam em áreas rurais pouco conhecidas, embora localizadas dentro de nações econômica e politicamente modernas. Grupos que estavam sendo esquecidos pelo processo de modernização ou que sofriam suas consequências. Assim, tendiam a manter suas características e resistir às mudanças. Por isso, os estudos de comunidade estavam "orientados essencialmente para o problema da mudança cultural" a que esses grupos estavam submetidos.

Nogueira (1955) cita Willems (1947), Herrmann (1948), Pierson (1951), Wagley (1953), Mussolini (1955), dentre outros, como exemplo de estudos comunitários. Afirma, ainda, que a denominação de estudos comunitários vinha sendo utilizada no Brasil para designar o

[...] estudo de grupos populacionais integrados em complexas estruturas nacionais, mais que ao de grupos indígenas relativamente isolados, é que se tem aplicado a designação; e a aplicação de tal perspectiva metodológica, no caso dos primeiros, suscita problemas e dificuldades especiais. (Nogueira, 1955, p. 95).

${ }^{27} \mathrm{O}$ conceito de comunidade é um dos mais clássicos em ciências sociais. Está presente em fundadores da sociologia como Durkheim ou Tonnies, assim como na tradição anglosaxônica. Para maiores detalhes sobre a utilização do conceito nessa tradição, ver Schreker (2006). 
Tanto para Wagley quanto para Nogueira, portanto, a semelhança analítica entre estudos rurais, comunitários e estudos imigrantistas não era fortuita, antes, afirmada. A temática e os conceitos utilizados indicam a proximidade entre estudos comunitários e aqueles de Emílio Willems (1940; 1944) ou de Egon Schaden (1956; 1959) sobre a aculturação de alemães e japoneses. Não admira, assim, que tenham sido os mesmos autores que realizaram essas pesquisas. A título de exemplo, ao analisar a aculturação de imigrantes alemães e japoneses, Schaden estabelece o seguinte paralelo com os estudos indigenistas:

Assim como a aculturação das populações indígenas em estado de marginalidade solicita o nosso interesse de um lado pelos resultados teóricos que o seu estudo promete e começa a surtir e de outro pela perspectiva de consequências práticas, também as pesquisas relativas às populações alienígenas trazidas da Europa e da Ásia, a partir do século passado, para incrementarem o desenvolvimento de nossa lavoura, se nos apresentam com essa duplicidade de aspectos (Schaden, 1956, p. 41).

O autor refere-se à "duplicidade de aspectos", ou seja, à marginalidade em que se encontravam tanto as populações indígenas quanto alienígenas, por um lado, e à necessidade de "desenvolvimento de nossa lavoura", por outro. $\mathrm{O}$ desenvolvimento da agricultura era esperado das comunidades rurais. De fato, parecia ser a questão rural - ou a questão do desenvolvimento agrícola a preocupação de todos. No artigo que publicou em 1959 sobre "problemas e aspectos do folclore teuto-brasileiro", Schaden ateve-se à problemática da mudança cultural, procurando avaliar as "[...] transformações sofridas pelo linguajar dos colonos no meio natural e cultural do Brasil" (Schaden, 1959 , p. 124). Isso era importante porque, como visto, o insulamento e a homogeneidade de muitas colônias de imigrantes prejudicavam, entre outras coisas, a nacionalização da linguagem e, por conseguinte, a integração dos descendentes. Fica claro, assim, por que as transformações culturais eram a chave para entender tanto a marginalização quanto a inserção à sociedade nacional. Em resumo, nenhuma daquelas comunidades parecia ter sido 
pensada a partir de idiossincrasias próprias, mas do ponto de vista de suas inserções no mercado agrícola e na sociedade nacional.

A semelhança e afinidade entre as abordagens utilizadas acima explicam, em parte, seu declínio. A questão que inicialmente levantamos diz respeito ao eclipse dos estudos imigrantistas. É possível supor que os estudos comunitários e, em alguma medida, certa vertente dos estudos indígenas padeceram de igual sorte. No caso dos estudos indígenas, o lento afastamento da corrente conhecida como "fricção étnica" levou junto consigo o arsenal teórico utilizado. É possível supor ainda que todos esses conceitos - assimilação, aculturação e absorção - fossem colonizadores demais, ou seja, estivessem preocupados tão somente em impor a sociedade nacional. Os imigrantes, tais como quaisquer outros membros de comunidades rurais, deveriam ser assimilados ou aculturados; numa palavra, deveriam perder qualquer característica que Ihes possibilitassem impor resistência à expansão das práticas de mercado e da modernidade ${ }^{28}$. Isso permite compreender a origem do lento eclipse dos estudos imigrantistas e, também, a associação de sua especificidade à questão da pequena propriedade rural, do café ou do tema geral da crise da agricultura (Martins, 1973). A consolidação da perspectiva de classe, a partir dos anos 1960, indicou o caminho: o imigrante não seria mais pensado como colono rural, mas sim como trabalhador, ou ainda como membro da classe trabalhadora, fosse ela rural ou urbana. Analisando o conjunto de estudos de comunidades que se faziam nos anos 1950 e denominando-os de estudos etnossociológicos sobre comunidades rurais, lanni afirmou:

A lenta, mas sistemática destruição da civilização agrária no Brasil, devido ao nascimento e à expansão do mundo urbano-industrial, tem provocado a elaboração de uma nova consciência histórica em grupos extensos da sociedade, da qual tendem a fazer parte essencial as categorias científicas criadas pelas ciências humanas. Daí a ênfase em estudos sobre mudanças sociais, aculturação e assimilação, problemas educacionais, condições de mobilidade social, causas

${ }^{28}$ A história dos estudos rurais ultrapassa em muito o escopo de nossa análise aqui. Mas é interessante pensar que os movimentos camponeses dos anos 1960 e/ou a importância dos assalariados rurais muito contribuíram para alterar radicalmente a perspectiva analítica que passou a ser empregada nesse campo de estudos nos anos 1960 e 1970. 
e efeitos das migrações, configurações de estruturas demográficas, "ciclos" económicos, subdesenvolvimento e crescimento económicos, crises e conflitos políticos, alterações nas estruturas do poder, formação da estrutura societária de classes, destruição dos remanescentes da sociedade escravocrata de castas, etc. (lanni, 1961, p. 109).

A passagem indica a correspondência entre esses estudos (imigrantistas, comunitários, rurais e indígenas): todos sofriam impactos do "mundo urbanoindustrial". Por isso, como afirma lanni, os estudos sobre mudança social, aculturação ou assimilação analisavam, de fato, as condições de mobilidade, os ciclos econômicos ou os conflitos políticos. Ou, ainda, avaliavam as consequências do avanço daquele "mundo urbano-industrial" que estava destruindo tanto a "civilização agrária" quanto a "sociedade escravocrata de castas". A trajetória dos estudos sobre imigrantes realizados nos anos 1960 confirma, de certa forma, a perspectiva apontada por lanni (1961) e endossada por Guimarães (1999) anos mais tarde:

Nesse contexto teórico, serão as classes sociais os principais agentes e o seu conceito a principal ferramenta da sociologia. A própria ideia de sociologia passa a ser associada ao conhecimento de uma estrutura (a estrutura social) regida por leis científicas e, portanto, racionalmente compreensível, mas totalmente opaca a entendimento dos indivíduos qua atores sociais. As relações sociais engendradas pelo processo de industrialização serão alçadas, portanto, à [sic] principal objeto de pesquisa, mas também - numa petição de princípios evidente - à condição de explicação mais plausível para os fenômenos mais diversificados.

Os anos 60 assistiram ao avanço da teoria das classes e à consolidação da influência do marxismo, e de todas as formas de explicação estrutural, na Sociologia brasileira. (Guimarães, 1999, p. 15).

À expansão analítica da perspectiva classista parece ter correspondido a generalização de uma crença segundo a qual os grupos de imigrantes e descendentes estavam se nacionalizando, seja devido às migrações internas, ou aos processos de socialização, ou, enfim, à expansão das relações de produção capitalista. $\mathrm{O}$ interessante é perceber que essa perspectiva de 
análise, dos conflitos e das classes, não era exatamente nova. Antes, já era anunciada na década anterior. Nos anos 1950, havia uma preocupação central em torno dos conflitos, ainda que os estudos imigrantistas continuassem a falar em processos de assimilação e de aculturação. Não por acaso, Izumi e Saito (1953), ao analisarem a "aculturação dos japoneses no Brasil", tomaram como critério o grau de desestruturação da "família nuclear" para, aí, verificar os níveis de aculturação. Assim fazendo, concluíram que "[...] a marcha da aculturação é muito mais acentuada no grupo da Amazônia do que no [de] São Paulo-Paraná" (Izumi; Saito, 1953, p. 209) ${ }^{29}$. Schaden (1956), retomando argumentos de Willems, afirmou então que tanto para imigrantes alemães quanto para japoneses, "[...] a integração dos imigrantes e de seus descendentes na comunidade nacional se processa através da luta por um status nessa comunidade, sendo decisivo o fato de a língua portuguesa e muitos elementos culturais brasileiros assumirem a função de fatores de distinção social." (Schaden, 1956, p. 46). Na antropologia, Ruth Cardoso $(1959 ;$ 1963), analisando o papel das associações juvenis e das novas profissões em relação à integração (ainda que parcial) e à ascensão social dos descendentes de japoneses, afirmou:

Atualmente a associação "nissei" aparece, pois, com função clara, criando condições para a aceitação de comportamentos novos, e mantendo a ligação do jovem à colônia através da preocupação de agir no sentido da ocidentalização e da procura de ascensão. Não se pode esquecer, porém, que esses grêmios recreativos são núcleos de segregação. Aí só convivem "nissei", impedindo um maior contato desses com jovens de outras origens. (Cardoso, 1959, p. 119).

As associações reuniam "nisseis", ou seja, descendentes de imigrantes japoneses nascidos no Brasil, que pretendiam se libertar da tutela dos pais japoneses. Em larga medida, era um conflito geracional aberto que

29 Saito era um imigrante japonês que chegou ao Brasil em 1933, no auge das políticas antinipônicas. Jesus e Taniguti afirmam que sua obra teve por objetivo "[...] éclairer à " rééduquer » les nisseis, à tracer « une voie plus ouverte, plus démocratique », en d'autres termes à réaliser une pleine intégration dans la société brésilienne". (Jesus; Taniguti, 2012, p. 211). 
sustentava o processo de aculturação. Em outro artigo, Cardoso (1963) analisou o processo de aculturação (ou de integração) dos descendentes de imigrantes japoneses, quando utilizou como variáveis os novos percursos educativos e as profissões escolhidas.

Para entender este desenvolvimento específico da aculturação dos japoneses, deve-se lembrar o papel dos velhos na criação dos ideais desta juventude. $\mathrm{Na}$ medida em que os filhos cumprem o que se espera deles, seu abrasileiramento é tolerado, pois é uma consequência de atitudes anteriores que devem ser aceitas e que se justificam plenamente dentro do universo da colônia japonesa urbanizada. (Cardoso, 1963, p. 59).

A oscilação no emprego de termos - abrasileiramento, aculturação e ocidentalização - indica a proximidade dos processos que se quer explicar. Os termos são luta, em Schaden, ascensão social, em Ruth Cardoso e mobilidade em Durham (1966). Enfim, mesmo na periferia intelectual do Brasil de então, em estudo sobre imigrantes residentes na região dos campos gerais paranaenses, Balhana e Boruszenko (1963, p. 331) concluíram que um "amplo e complexo processo de aculturação" ali também se desenvolvia. Como um todo, esses artigos apontam para uma conclusão quase unânime: os imigrantes e seus descendentes estavam em franco processo de aculturação e de integração. Não havia mais razão para estudá-los em relação à sociedade nacional, porque nela estavam bastante inseridos. Por isso, a virada históricoconceitual, na forma da consolidação da perspectiva classista, não teria sido traumática, antes orgânica, e isso também explica o eclipse dos estudos imigrantistas a que nos referimos, que foi também, em parte, o eclipse de determinado tipo de estudos comunitários e rurais.

\section{Considerações finais}

O Estado brasileiro, desde o período imperial até a primeira metade do século XX, desenvolveu uma política de imigração seletiva, cujo objetivo era assimilar grupos imigrantes e negar substratos culturais específicos. Resumidamente, isso ocorreu em duas vertentes que disputaram espaços 
e visões, mas nem sempre se opuseram. De um lado, a política imigrantista sustentou-se sobre o desejo mal disfarçado de atrair imigrantes europeus brancos que contribuíssem para "branquear" a população nativa. Essa política teve início no século XIX. Esteve ligada ao ambiente racial e científico da época e, sobretudo, à crença segundo a qual o principal problema do Brasil era justamente o povo miscigenado com fortes traços indígenas e negros. De outro lado, a política imigrantista esteve ligada aos interesses econômico-demográficos, seja das elites cafeicultoras paulistas, seja das elites imperiais e republicanas dos estados sulinos, cujo objetivo principal era tanto atrair trabalhadores para o café quanto povoar e cultivar as áreas ditas vazias e, assim, resolver os problemas de abastecimento de alimentos. Apesar das diferenças, as duas vertentes sempre se afinaram num ponto central: o imigrante deveria ser assimilado à sociedade nacional. Teria essa crença no processo assimilativo desafiado os cientistas sociais do período e, de certa forma, pautado suas perspectivas analíticas?

No final dos anos 1930 e meados da década de 1940, o tema da assimilação dos imigrantes ganhou grande destaque quando da publicação dos decretos nacionalizadores, fazendo com que a política imigrantista deixasse de ser apenas eugênica para tornar-se assunto de segurança do Estado. Naqueles anos, o objetivo extraoficial foi limitar e/ou impedir a entrada dos grupos ditos inferiores, mormente negros, japoneses e judeus, privilegiando assim o chamado imigrante ideal (Geraldo, 2007; Koifman, 2012). Com o retorno à democracia, o tema da assimilação dos imigrantes esteve presente nos debates da Constituinte de 1946, em especial graças à atuação do deputado Gilberto Freyre (Oliveira, 2017).

Ao final dos anos 1950, porém, a política imigrantista havia saído do centro da cena e a questão imigrante pareceu, à jovem geração de cientistas sociais que se afirmava, como comunitária demais e nacional de menos. As comunidades de imigrantes pareciam estar assimiladas e aculturadas ou em franco processo de assimilação e aculturação, não necessariamente devido à ação do Estado, mas devido a seu próprio interesse em participar da vida social, econômica e política do país. Antropólogos como Eduardo Galvão 
e Ruth Cardoso, e sociólogos como Florestan Fernandes e Octávio lanni demonstraram, cada um a seu modo, o caráter limitado da perspectiva assimilação/aculturação, quando se tratava de analisar os processos de mudança social a que estava submetido todo e qualquer grupo, rural ou imigrante. Contudo, como mostramos, há paralelos e continuidades entre a perspectiva classista dos anos 1960 e 1970 e a perspectiva assimilacionista/ aculturalista das décadas precedentes. Ao final, porém, o abandono do referencial teórico da assimilação/aculturação acabaria por levar consigo o tema de estudo. É isso que chamamos de eclipse.

Não obstante a crença daquele período, no final do século XX, Christian Gros, sociólogo e latino-americanista, refletiu sobre a dificuldade de integração das populações rurais e indígenas nos mais diversos países da América Latina. No interior das políticas de modernização das atividades econômicas, afirmou, escondiam-se os mais diversos tipos de manipulação das identidades étnicas das populações indígenas e rurais (Gros, 1997). De certo modo, o mesmo poderia ser dito das populações imigrantes. De meados dos anos 1970 em diante, já consideradas brasileiras, assimiladas e integradas, não eram mais objeto da sociologia, mas da história e, por vezes, da antropologia. Nessa última, muitos foram os estudos, em especial nos últimos 30 anos, que resgataram inúmeras persistências sociais e culturais, nuançando o vaticínio dos anos 1960 e 1970. Descendentes de imigrantes não foram necessariamente assimilados ou aculturados. São todos brasileiros e estão, em graus diversos, integrados à sociedade nacional. Porém, aqui e ali, heranças foram criadas e reproduzidas, alianças matrimoniais mantidas e práticas culturais atualizadas, explicando talvez as razões para o ressurgimento desse tipo de culto estratégico de uma ancestralidade europeia, de resto mal conhecida, mas bastante acionada como forma de distinção social. Porém, o que pretendemos demonstrar, de um lado, foi o diálogo entre antropologia e sociologia e o uso comum de termos e referências teóricas. De outro, que os conceitos de assimilação e aculturação, vale insistir, não foram utilizados para evidenciar idiossincrasias, mas processos de mudança social. Por isso, 
não se pode falar que estavam distantes dos conceitos de classe ou da perspectiva do conflito, antes os anunciaram. De certo modo, a sociologia da imigração daquele período era menos disciplinar do que se tornou hoje. Pensar assim é mostrar a importância dos estudos imigracionistas e sua contribuição para a história da sociologia no Brasil.

Márcio de Oliveira é Professor Titular de Sociologia da Universidade Federal do Paraná (UFPR).

$\equiv$ marciodeoliveira62@gmail.com

\section{Referências}

1. ALMEIDA, Renato de. O folclore como elemento nacionalizador dos colonos estrangeiros. Revista de Imigração e Colonização, Rio de Janeiro, ano IV, n. 1, p. 58-67, 1943.

2. ASSIS, Gláucia de O.; SASAKI, Elisa M.; SALES, Teresa. Os novos e/imigrantes do e para o Brasil: um balanço da bibliografia. Anais do XXVII Encontro Anual da Anpocs, 2003.

3. AZEVEDO, Aluísio Assimilação. Sociologia, São Paulo, v. III, n. 2, p. 149-150, 1941.

4. ARRUDA, Maria A.do N.; GARCIA, Sylvia G. Florestan Fernandes: mestre da sociologia moderna. Paralelo 15: Brasília, 2003.

5. ARRUDA, Maria A. do N. Florestan Fernandes, vocação científica e compromisso de vida. In: BOTELHO, André; SCHWARCZ, Lilia M. (orgs.). Um enigma chamado Brasil. 29 intérpretes e um país. Cia das Letras, 2009, p. 310-323.

6. BAENINGER, Rosana (org.). Imigração Boliviana no Brasil. Campinas: NEPPO/ FAPESP/CNPq/Unfpa, 2012.

7. BALHANA, Altiva P.; BORUSZENKO, Oksana. Alguns problemas de aculturação nos Campos Gerais. Revista do Museu Paulista, São Paulo, N. S., v. XIV, p. 322331, 1963.

8. BASTOS, Elide R. (org.). Florestan Fernandes ou o sentido das coisas. São Paulo: Boitempo, 1998.

9. BETHLEM, Hugo. Vale do Itajaí. Jornadas de Civismo. Rio de Janeiro: Livraria José Olympio Editora, 1939.

10. BLANCO, Alejandro; JACKSON, Luís C. Florestan no espelho de Germani. Sociologia e Antropologia. Rio de Janeiro, v. 4, n. 1, p. 127-161, 2014. 
11. BOSCHILIA, Roseli. O cotidiano de Curitiba durante a II Guerra Mundial. Boletim Informativo da Casa Romário Martins. Curitiba: Fundação Cultural, 1995, p. 1-65.

12. BRASIL Jr., Antônio. O imigrante e seus irmãos: as pesquisas empíricas de Florestan Fernandes e Gino Germani. Lua Nova, Campinas, n. 81, p. 175-213, 2010.

13. BREPOHL DE MAGALHÃES, Marionilde D. Pangermanismo e nazismo: a trajetória alemã rumo ao Brasil. Campinas: Editora da Unicamp, 1998.

14. CAMPOS, Cíntia M. A política da língua na era Vargas. Campinas: Editora da UNICAMP, 2006.

15. CARDOSO, Ruth C. L. O papel das associações juvenis na aculturação dos japoneses. Revista de Antropologia, v. 7, n. 1-2, p. 101-122, 1959.

16. CARDOSO, Ruth C. L. O agricultor e o profissional liberal entre os japoneses no Brasil. Revista de Antropologia, São Paulo, v. XI, n. 1-2, p. 53-60, 1963.

17. CARDOSO DE OLIVEIRA, Roberto. Preliminares de uma pesquisa sobre a assimilação dos Terêna. Revista de Antropologia, v. V, n. 2, p. 173-188, 1957.

18. CARDOSO DE OLIVEIRA, Roberto. Do índio ao bugre. O Processo de Assimilação dos Terena. Rio de Janeiro: Livraria F. Alves Editora, 2a ed, [1960] 1976.

19. CASTRO, Eduardo Viveiros de. Etnologia brasileira. In: MICELI, Sergio (org.). O que ler na ciência social brasileira (1970-1995). Antropologia (volume I). São Paulo: Editora Sumaré: ANPOCS; Brasília, DF: CAPES, 1999, p. 109-223.

20. CECCHI, Camilo. Estudo comparativo da assimilação e marginalidade do imigrante italiano. Sociologia, São Paulo, v. XIX, n. 2, p. 105-117, 1957.

21. CHAPOULIE, Jean-Michel. La tradition sociologique de Chicago. Paris: Seuil, 2001.

22. CIACCHI, Andréa. Gioconda Mussolini, uma trajetória biográfica. Revista de Antropologia, v. 50, n. 1, p. 181-223, 2007.

23. CONSORTE, Josildeth G. Os estudos de comunidade no Brasil: uma viagem no tempo. In: FALEIROS, Maria I. L.; CRESPO, Regina A. (orgs.). Humanismo e compromisso: ensaios sobre Octávio lanni. São Paulo: Editora da UNESP, 1996, p. 51-68.

24. DOYTCHEVA, Milena. Le multiculturalisme. Paris, Ed La Découverte, Coll. Repères, 2011.

25. DURHAM, Eunice. Assimilação e mobilidade. São Paulo: IEB. 1966

26. DURKHEIM, Émile. As formas elementares da vida religiosa. São Paulo: Martins Fontes, 2002. 
27. DURKHEIM, Emile; MAUSS, Marcel. Algumas formas de classificação primitiva. In: RODRIGUES, José A. Emile Durkheim: Sociologia. São Paulo: Editora Ática, Coleção Grandes Cientistas Sociais, 2a ed., 1981, p. 183-203.

28. ELLIS Jr., Alfredo. Populações paulistas. São Paulo: CEN, 1934.

29. EINSENSTADT, Shmuel N. The absorption of immigrants: a comparative study based mainly on the Jewish community in Palestine and the State of Israel. Londres: Routledge and Paul Kegan, 1954.

30. FAIRCHILD, Henry P. Immigration. A world movement and its American significance. New York: Macmillan Co., [1913] 1941.

31. FERNANDES, Florestan. A análise sociológica das classes sociais. Sociologia, v. 10, n. $2-3,1948$

32. FERNANDES, Florestan. Resenha de $A$ aculturação dos alemães no Brasil de Emilio Willems. Revista do Arquivo Municipal, ano XV, v. CXXII, n. 2, p. 205-218, 1949.

33. FERNANDES, Florestan. A aculturação do sírio e libanês em São Paulo. Folha da Manhã, n. 9842, 10 de junho, p. 1-2, 1956a.

34. FERNANDES, Florestan. A aculturação dos sírios e libaneses em São Paulo. Revista Etapas, ano I, n. 11, 1956 b.

35. FERNANDES, Florestan. A etnologia e a sociologia no Brasil. São Paulo, Anhembi, 1958.

36. FERNANDES, Florestan. Imigração e relações raciais. Revista de Civilização Brasileira. Ano 1, n. 8, p. 75-95, 1966.

37. FREYRE, Gilberto. Continente e ilha. Rio de Janeiro: Edição da Casa do Estudante do Brasil, 1943.

38. GALVÃO, Eduardo. Estudo sobre aculturação de grupos indígenas. Trabalho apresentado à 1ạ Reunião da Associação Brasileira de Antropologia (ABA), Rio de Janeiro, 1953. Disponível em: <http://www.periodicos.usp.br/ra/article/ viewFile/110360/108927> Acesso em: 14 abr. 2017.

39. GARCIA, Sylvia G. Destino ímpar: sobre a formação de Florestan Fernandes. Editora 34: São Paulo, 2002.

40. GERALDO, Endrica. O "perigo alienígena". Política migratória no Governo Vargas (1930-1945). Tese (Doutorado em História) - Instituto de Filosofia e Ciências Humanas, Universidade Estadual de Campinas, SP, 2007

41. GREEN, Nancy. O tempo e o estudo da assimilação. Antropolítica, n. 25, 2oㅡㄴ sem, p. 23-47, 2008.

42. GROS, Christian. Pour une sociologie des populations indiennes et paysannes de I'Amérique Latine. Paris: L'Harmattan, 1997. 
43. GUIMARÃES, Antônio S. A. Classes sociais. In: MICELI, Sérgio (org.). O que ler na ciência social brasileira. São Paulo: Ed. Sumaré, v. 2, 1999, p. 13-54.

44. HERRMANN, Lucila. Evolução da estrutura social de Guaratinguetá num período de trezentos anos. Revista de Administração, São Paulo, ano II, n. 5-6, p. 1-326, mar.-jun., 1948.

45. JESUS, Mateus G. de; TANIGUTI, Gustavo T. Sociologie de l'immigrant : Hiroshi Saito et l'institutionnalisation des études sur les japonais du Brésil (19401960). Brésil(s), Paris, v. 2, p. 201-222, 2012.

46. IANNI, Octávio. Estudo de comunidade e conhecimento científico. Revista de Antropologia, v. 9, n. 1-2, p. 109-119, 1961.

47. INCAO, Maria A. O saber militante: ensaios sobre Florestan Fernandes. Rio de Janeiro: Paz e Terra, 1987.

48. INSTITUTO SUPERIOR BRASILEIRO-ITALIANO DE ESTUDOS E PESQUISAS. Imigração italiana. Estudos. Conferências e debates apresentados durante o 10 e o $2^{\text {O }}$ Fórum de Estudos Ítalo-Brasileiros. Caxias do Sul: UCS/Porto Alegre: Escola Superior de Teologia São Lourenço de Brindes, 1979.

49. IZUMI, Seiichi; SAITO, Hiroshi. Pesquisa sobre aculturação dos japoneses no Brasil. Sociologia, São Paulo, v. XV, n. 3, p. 195-209, 1953.

50. KOFFES, Suely. As pedras e o arco: os estudos de comunidade e a atualidade de antigas questões. In: FALEIROS, Maria I. L.; CRESPO, Regina A. (orgs.). Humanismo e compromisso: ensaios sobre Octávio lanni. São Paulo: Editora da UNESP, 1996, p. 41-50.

51. KOIFMAN, Fábio. Imigrante ideal. O Ministério da Justiça e a entrada de estrangeiros no Brasil (1941-1945). Rio de Janeiro: Civilização Brasileira, 2012.

52. LIEDKE FILHO, Enno D. A sociologia no Brasil: história, teorias e desafios. Sociologias, Porto Alegre, v. 7, n. 14, p. 376-436, 2005.

53. LIMONGI, Fernando. A Escola Livre de Sociologia e Politica em São Paulo. In: MICELI, Sérgio. História das Ciências Sociais no Brasil. v. 1, São Paulo: Vértice: IDESP, FINEP, 1989, p. 257-276.

54. LOPES, Lívia B. F.; VILELA, Elaine M. Balanço da produção acadêmica sobre migração internacional no Brasil. BIB, n. 72, p. 55-88, 2011.

55. MACAGNO, Lorenzo. O dilema multicultural. Curitiba, Editora UFPR; Rio de Janeiro, Graphia, 2014.

56. MARTINS, José de S. Imigração e a crise do Brasil agrário. São Paulo: Pioneira, 1973.

57. MASSI, Fernanda. Franceses e norte-americanos nas ciências sociais brasileiras. In: MICELI, S. (Org.) História das ciências sociais no Brasil. São Paulo: Vértice, Editora Revista dos Tribunais; IDESP, 1989, p. 410-459.

58. MAUSS, Marcel; FAUCONNET, Paul. La sociologie. Objet et méthode. Année Sociologique, v. 30, p. 3-26, 1901. 
59. MAUSS, Marcel. Appréciation sociologique du bolchevisme. Revue de Métaphysique et de Morale, Paris, tome 31, v.1, p. 103-132, 1924.

60. MAUSS, Marcel. La cohésion sociale dans les sociétés polysegmentaires. Communication présentée à l>Institut français de sociologie. Bulletin de l'Institut Français de Sociologie, I, p. 3-12, 1931.

61. MAUSS, Marcel. La sociologie en France de 1914 à 1933. Science Française, tomo I, p. 36-46, 1933.

62. MAUSS, Marcel. Fragments d’un Plan de Sociologie Générale Descriptive. Classification et méthode d'observation des phénomènes généraux de la vie sociale dans les sociétés de types archaïques (phénomènes généraux spécifiques de la vie intérieure de la société), Annales Sociologiques, série A, fascículo I, p. 4-36, 1934.

63. MUSSOLINI, Gioconda. Persistência e mudança em sociedades de folk no Brasil. Anais do XXXI Congresso Internacional de Americanistas, v. I, São Paulo Anhembi, 1955, p. 333-353.

64. NISBET, Robert A. La tradition sociologique. Paris: PUF, coll. Quadrige., 1993 65. NOGUEIRA, Oracy. Os estudos de comunidades no Brasil. Revista de Antropologia, São Paulo, v. 3, n. 2, p. 95-102, 1955.

66. OLIVEIRA, Denisson de. Os soldados alemães de Vargas. Curitiba: Juruá, 2008.

67. OLIVEIRA, Márcio de. Em torno da Civilização luso-tropical: a contribuiçãa de Gilberto Freyre à sociologia da imigração no Brasil. Cadernos CRH, Salvador, v. 30, n. 81, p. 561-578, 2017.

68. OLIVEIRA VIANA, Francisco J. Raça e assimilação. São Paulo: Companhia Editora Nacional, 1934.

69. PACHECO, Renato J. C. Assimilação de alemães no Espírito Santo. Sociologia, São Paulo, v. XXVI, n. 2, p. 183-201, 1964.

70. PARK, Robert. Human migration and marginal man. American Journal of Sociology, New York, v. XXXVII, n. 6, p. 881-893, 1928.

71. PATARRA, Neide L. Migrações Internacionais de e para o Brasil contemporâneo: volumes, fluxos, significados e políticas. São Paulo em Perspectiva, São Paulo, v. 19, n. 3, p. 23-33, 2005.

72. PEIXOTO, Fernanda A.; SIMÕES, Julio A. A Revista de Antropologia e as ciências sociais em São Paulo: notas sobre uma cena e alguns debates. Revista de Antropologia, São Paulo, USP, v. 46, n. 2, 2003.

73. PEREIRA, João Batista. B. Italianos no mundo rural paulista. São Paulo: Pioneira/IEB-USP, 1973.

74. PEREIRA, João Batista. B. Emilio Willems e Egon Schaden na história da antropologia. Estudos Avançados, São Paulo, v. 8, n. 22, p. 249-253, 1994. 
75. PIERSON, Donald. Como é descobrir 'classe'. Sociologia, São Paulo, v. X, n. 2-3, p. 73-91, 1948.

76. PIERSON, Donald. Cruz das Almas, a Brazilian Village. Washington: Smithsonian Institution. Institute of Social Anthropology. Publication n. 12, 1951.

77. QUEIROZ, Maria I. P. de. Assimilação de três famílias em São Paulo. Sociologia, São Paulo, v. XII, n. 1, p. 22-32, 1950.

78. RIBEIRO, Mariana C. Venha o decreto da expulsão: a legitimação da ordem autoritária no governo Vargas (1930-1945). São Paulo: Humanistas, 2012.

79. RIOS, José A. Aspectos políticos da assimilação do italiano no Brasil. Sociologia, São Paulo, v. XX, p. 295-339, 1958.

80. ROSS, Dorothy. The origins of American social science (Ideas in Context). Cambridge: Cambridge University Press, 1991.

81. SAITO, Hiroshi; WILLEMS, Emílio. Shindô-Renmei. Um problema de aculturação. Sociologia, São Paulo, v. IX, n. 2, p. 133-152, 1947.

82. SAITO, Hiroshi; MAYEMA, Takashi (orgs.). Assimilação e integração dos japoneses no Brasil. Petrópolis/São Paulo: Vozes/Edusp, 1973.

83. SCHADEN, Egon. Aculturação de alemães e japoneses no Brasil. Revista de Antropologia, São Paulo, v. 4, n. 1, p. 41-46, 1956.

84. SCHADEN, Egon. Alguns problemas e aspectos do folclore teuto-brasileiro. Revista de Antropologia, v. 7, n. 1-2, p. 123-135, 1959.

85. SCHRECKER, Cherry. La communauté. Histoire critique d'un concept dans la sociologie anglo-saxonne. Paris: L'Harmattan, 2006.

86. SILVA, Sydnei A. Bolivianos em São Paulo. Dinâmica cultural e processos identitários. In BAENINGER, Rosana (org.). Imigração boliviana no Brasil. Campinas: NEPPO/FAPESP/CNPq/Unfpa, p. 19-34, 2012.

87. SOARES, Eliane V. Florestan Fernandes: o militante solitário. Rio de Janeiro: Cortez. 16, 1997.

88. STEPAN, Nancy L. A hora da eugenia. Raça, gênero e nação na América Latina. Rio de Janeiro: Editora Fiocruz, 2005.

89. TRUZZI, Osvaldo. Assimilação ressignificada: novas interpretações de um velho conceito. Dados, Rio de Janeiro, v. 55, n.2, p. 517-553, 2012.

90. VILLAS-BÔAS, Gláucia. De Berlim a Brusque, de São Paulo a Nashville. A sociologia de Emílio Willems entre fronteiras. Tempo Social. Revista de Sociologia da USP, São Paulo, v. 12, n. 2, p. 171-188, 2000.

91. WAGLEY, Charles. Amazon town: a study of man in the tropics. New York: The Macmillan Company, 1953.

92. WAGLEY, Charles. Estudos de comunidade no Brasil sob perspectiva nacional. Sociologia, São Paulo, v. XVI, n. 2, p. 3-22, 1954. 
93. WILLEMS, Emilio. Assimilação de populações marginais do Brasil. São Paulo: Cia Editora Nacional, 1940.

94. WILLEMS, Emilio. Acculturation and the horse complex among German-Brazilians. American Anthropologist, Washington, New Series, v. 46, n. 2, p. 153-161, 1944.

95. WILLEMS, Emilio. Assimilação dos judeus. Sociologia, São Paulo, v. III, n. 1-2, p. 54-77, 1945.

96. WILLEMS, Emilio. A aculturação dos alemães no Brasil. São Paulo: Cia Editora Nacional, 1946.

97. WILLEMS, Emilio. Cunha. Tradição e transformação em uma cultura rural do Brasil. São Paulo: Secretaria de Agricultura, 1947.

98. WILLEMS, Emilio. Aspectos da aculturação dos japoneses no estado de São Paulo. São Paulo: Ed da USP, 1948.

99. WILLEMS, Emilio. The structure of the Brazilian family. Social Forces, North Caroline, v. 31, n. 4, p. 339-345, 1953. 